\title{
Polyphasic taxonomy of the basidiomycetous yeast genus Rhodosporidium: Rhodosporidium kratochvilovae and related anamorphic species
}

\author{
José Paulo Sampaio, ${ }^{1}$ Mário Gadanho, ${ }^{1}$ Sofia Santos, ${ }^{2}$ \\ Filomena L. Duarte, ${ }^{2,3}$ Célia Pais, ${ }^{3}$ Álvaro Fonseca ${ }^{1}$ and Jack W. Fell ${ }^{4}$
}

Author for correspondence: José Paulo Sampaio. Tel: +35121 2948300. Fax: +351212948530. e-mail: jss@mail.fct.unl.pt

1 Centro de Recursos Microbiológicos, Secção Autónoma de Biotecnologia, Faculdade de Ciências e Tecnologia, Universidade Nova de Lisboa, 2825-114 Caparica, Portugal

2 Estação Vitivinícola Nacional, INIA, 2565-191 Dois Portos, Portugal

3 Centro de Ciências do Ambiente, Departamento de Biologia, Universidade do Minho, 4710-057

Braga, Portugal

4 Rosenstiel School of Marine and Atmospheric Science, University of Miami, 4600 Rickenbacker Causeway, Key Biscayne, FL 33419, USA
The phenotypic and genetic heterogeneity of the basidiomycetous yeast species Rhodosporidium kratochvilovae was investigated in a group of recent isolates and collection strains. A polyphasic taxonomic approach was followed which included micromorphological studies, nuclear staining, determination of sexual compatibility, physiological characterization, comparison of electrophoretic isoenzyme patterns, PCR fingerprinting, determination of mol \% G+C, DNA-DNA reassociation experiments and 265 and ITS rDNA sequence analysis. The results allowed a more natural circumscription of the species, both from the genetic and phenotypic perspectives. The relationships with anamorphic species of the genus Rhodotorula were studied and isolates previously identified as Rhodotorula glutinis were found to belong to Rhodosporidium kratochvilovae. Other isolates included in the study were found to represent members of $R$ hodotorula glutinis var. dairenensis. Rhodosporidium kratochvilovae was found to include heterothallic strains, besides those already known to be self-sporulating. A total of 17 isolates, which were found to belong to this species, were heterothallic, selfsporulating and anamorphic strains. It is anticipated that integrated polyphasic studies of basidiomycetous yeasts will provide a more coherent classification system and the basis for accurate identification schemes, which in turn are essential for detailed ecological studies.

Keywords: basidiomycetous yeasts, polyphasic taxonomy, Rhodosporidium kratochvilovae, Rhodotorula glutinis

\section{INTRODUCTION}

The heterobasidiomycetous yeast species Rhodosporidium kratochvilovae Hamamoto, Sugiyama et Komagata was described by Hamamoto et al. (1988) to accommodate two self-sporulating strains (YK $218=$ IGC 4583 and YK $219=$ IGC 5579) previously classified in Rhodosporidium toruloides Banno. The combination of several taxonomic criteria such as life cycle, electrophoretic mobility of selected enzymes (Yamazaki \& Komagata, 1981; Hamamoto et al., 1986a), ubiquinone system (Sugiyama et al., 1985), mol \% G + C (Hamamoto et al., 1986b) and DNADNA reassociation values (Hamamoto et al., 1987)

Dedicated to the memory of Dr Cecília Cabeça-Silva, who isolated some of the Rhodosporidium kratochvilovae strains studied in this work. supported the proposal of Rhodosporidium kratochvilovae as a distinct species. Two other strains (YK $102=$ IGC 5580 and YK $103=$ IGC 4883) were found to be closely related to Rhodosporidium kratochvilovae due to similarities in electrophoretic patterns of enzymes (Yamazaki \& Komagata, 1981; Hamamoto et al., 1986a) and high DNA-DNA reassociation values (Hamamoto et al., 1987). These two strains fit the concept of Rhodotorula glutinis (Fresenius) Harrison and were regarded as the anamorphic stage of Rhodosporidium kratochvilovae, since they were unable to produce mycelium with teliospores (Hamamoto et al., 1988).

Studying recent isolates and collection strains, we investigated the degree of phenotypic and genetic heterogeneity in Rhodosporidium kratochvilovae and examined its relationships with anamorphs like Rho- 
dotorula glutinis. A polyphasic taxonomic approach was followed which included micromorphological studies, nuclear staining, determination of sexual compatibility, physiological characterization, comparison of isoenzyme electrophoretic patterns, PCR fingerprinting, rDNA sequence analysis, determination of $\mathrm{mol} \% \quad \mathrm{G}+\mathrm{C}$ and DNA-DNA reassociation experiments.

\section{METHODS}

Cultures. A total of 40 strains of Rhodosporidium kratochvilovae and related teleomorphic and anamorphic species were investigated. The list of cultures used in this study is presented in Table 1.

Morphological characterization and studies of sexual com- patibility. For microscopy, cultures were grown on cornmeal agar (CMA) or MYP agar (Bandoni, 1972) at room temperature $\left(20-23^{\circ} \mathrm{C}\right)$ and studied with phase-contrast optics. For determination of sexual compatibility, pairs of 2-4-d-old cultures were crossed on CMA, incubated at room temperature and examined for production of mycelium and teliospores after 1 week. Teliospore germination was investigated after 8-10 weeks. Alternatively, 4-6-week-old teliospores were harvested, soaked in demineralized water for 2 weeks, transferred to water agar and examined after $2-3 \mathrm{~d}$.

Nuclear staining. For nuclei observation, a modified Giemsa staining protocol was used. Cultures were grown on CMA for 1 week and an agar block of approximately $5 \mathrm{~mm} \times 5 \mathrm{~mm}$ was cut from a mycelium-containing area. The agar block was placed on a glass slide, and finely cut to small pieces that were allowed to dry for $1 \mathrm{~h}$. Then the specimens were fixed in a mixture of $3: 1$ ethanol/glacial acetic acid for $30 \mathrm{~min}$,

Table 1 List of strains used in this study

Strains are listed with their original names and those that were renamed during this study are indicated with an asterisk. Their correct designation is listed in Table 2.

\begin{tabular}{|c|c|c|c|}
\hline Species & Strain no. $\dagger$ & Strain origin $\div$ & Isolation source \\
\hline Rhodosporidium babjevae Golubev & IGC $5168^{\mathrm{T}}$ & VKM Y-2275 & Herbaceous plant, Moscow, Russia \\
\hline Rhodosporidium babjevae & IGC 5169 & VKM Y-2276 & Herbaceous plant, Moscow, Russia \\
\hline Rhodosporidium diobovatum Newell et Hunter & IGC $4364^{\mathrm{T}}$ & CBS $6085^{\mathrm{T}}$ & Seawater, USA \\
\hline Rhodosporidium diobovatum & IGC 4640 & CBS 6084 & Seawater, USA \\
\hline Rhodosporidium fluviale Fell, Kurtzman, Tallman et Buck & IGC $4701^{\mathrm{T}}$ & CBS $6568^{\mathrm{T}}$ & Brackish water, USA \\
\hline Rhodosporidium kratochvilovae Hamamoto, Sugiyama et Komagata & IGC $4583^{\mathrm{T}}$ & IAM $13072^{\mathrm{T}}$ & Unknown \\
\hline Rhodosporidium kratochvilovae & IGC 5579 & JCM 8172 & Unknown \\
\hline Anamorph of Rhodosporidium kratochvilovae & IGC 4883 & JCM 3772 & Unknown \\
\hline Anamorph of Rhodosporidium kratochvilovae & IGC 5580 & JCM 8173 & Unknown \\
\hline Rhodosporidium lusitaniae Fonseca et Sampaio & IGC $4641^{\mathrm{T}}$ & & Woodland soil, Lisbon, Portugal \\
\hline Rhodosporidium lusitaniae & IGC 4599 & & Dry leaf, Arrábida, Portugal \\
\hline Rhodosporidium paludigenum Fell et Statzell-Tallman & IGC $4495^{\mathrm{T}}$ & CBS $6566^{\mathrm{T}}$ & Juncus roemerianus marsh, USA \\
\hline Rhodosporidium paludigenum & IGC 4496 & CBS 6567 & Rhizophora mangle marsh, USA \\
\hline Rhodosporidium sphaerocarpum Newell et Fell & IGC $4104^{\mathrm{T}}$ & CBS $5939^{\mathrm{T}}$ & Water, Antarctica \\
\hline Rhodosporidium sphaerocarpum & IGC 4105 & CBS 5940 & Seawater, Antarctica \\
\hline Rhodosporidium toruloides Banno & IGC 4416 & CBS 14 & Wood pulp, Sweden \\
\hline Rhodosporidium sp.* & IGC 4793 & & Grasshopper, Sintra, Portugal \\
\hline Rhodosporidium sp.* & IGC 4818 & & Wood chips, Setúbal, Portugal \\
\hline Rhodosporidium sp.* & IGC 4819 & & Moss, Oeiras, Portugal \\
\hline Rhodotorula araucariae Grinbergs et Yarrow & IGC $4625^{\mathrm{T}}$ & CBS $6031^{\mathrm{T}}$ & Rotting bark of Araucaria araucana, Chile \\
\hline Rhodotorula glutinis (Fresenius) Harrison var. glutinis & IGC $4177^{\mathrm{T}}$ & CBS $20^{\mathrm{T}}$ & Air \\
\hline Rhodotorula glutinis var. glutinis & IGC 4706 & & Reed, Oeiras, Portugal \\
\hline Rhodotorula glutinis var. glutinis* & IGC 4776 & & Leaf, Oeiras, Portugal \\
\hline Rhodotorula glutinis var. glutinis* & IGC 4778 & & Pine cone, Oeiras, Portugal \\
\hline Rhodotorula glutinis var. glutinis & IGC 4780 & & Blackberries, Sesimbra, Portugal \\
\hline Rhodotorula glutinis var. glutinis & IGC 4781 & & Dead leaves, Oeiras, Portugal \\
\hline Rhodotorula glutinis var. glutinis* & IGC 4783 & & Polipore fungus, Arrábida, Portugal \\
\hline Rhodotorula glutinis var. glutinis* & IGC 4785 & & Plant litter, Arrábida, Portugal \\
\hline Rhodotorula glutinis var. glutinis* & IGC 4787 & & Seawater, Arrábida, Portugal \\
\hline Rhodotorula glutinis var. glutinis* & IGC 4784 & & Plant litter, Arrábida, Portugal \\
\hline Rhodotorula glutinis var. glutinis* & IGC 4897 & & Flower of Canna indica, Azores, Portugal \\
\hline Rhodotorula glutinis var. glutinis* & IGC 5068 & & Soil, Azores, Portugal \\
\hline Rhodotorula glutinis var. glutinis* & IGC 5085 & & Soil, Azores, Portugal \\
\hline Rhodotorula glutinis var. glutinis* & IGC 5244 & & Culture contaminant, Oeiras, Portugal \\
\hline Rhodotorula glutinis var. glutinis* & IGC $5591 \S$ & CBS 332 & Sputum \\
\hline Rhodotorula glutinis var. glutinis* & IGC $5606 \|$ & CBS 321 & Air, Japan \\
\hline Rhodotorula glutinis var. dairenensis Hasegawa \& Banno & IGC $4885^{\mathrm{T}}$ & $\mathrm{JCM} 3774^{\mathrm{T}}$ & Unknown \\
\hline Rhodotorula graminis di Menna & IGC $4842^{\mathrm{T}}$ & CBS $2826^{\mathrm{T}}$ & Grass, New Zealand \\
\hline Rhodotorula mucilaginosa (Jörgensen) Harrison & IGC $5166^{\mathrm{T}}$ & CBS $316^{\mathrm{T}}$ & Unknown \\
\hline Rhodotorula mucilaginosa & IGC 4759 & & Marsh water, Setúbal, Portugal \\
\hline
\end{tabular}

$\dagger$ IGC, Portuguese Yeast Culture Collection, FCT-UNL, Portugal; ${ }^{\mathrm{T}}$, type strain.

$\$ C B S$, Centraalbureau voor Schimmelcultures, Yeast Division, Delft, The Netherlands; IAM, Institute of Molecular and Cellular Biosciences, University of Tokyo, Japan; JCM, Japan Collection of Microorganisms, RIKEN, Japan; VKM, All-Russian Collection of Microorganisms, Moscow, Russia.

§ Type strain of Torulopsis bronchialis Ciferri et Redaelli.

|| Type strain of Torula rufula Saito. 
washed in demineralized water, hydrolysed in $1 \mathrm{M} \mathrm{HCl}$ at $55-60{ }^{\circ} \mathrm{C}$ for $7 \mathrm{~min}$, and washed again in $0 \cdot 1 \mathrm{M}$ sodium phosphate buffer ( $\mathrm{pH} 7$ ). Specimens were then stained for $2 \mathrm{~h}$ in a 1:9 Giemsa (Merck)/phosphate buffer solution. Excess stain was removed by washing with demineralized water. After the slides had dried completely, they were mounted permanently in entellan (Merck).

Physiological characterization. Physiological and biochemical characterization was performed according to the techniques described by Yarrow (1998). Additional assimilation tests were performed using aldaric acids and aromatic compounds, as described by Fonseca (1992) and Sampaio (1999), respectively. The results of the 71 tests selected by Sampaio \& Fonseca (1995) were used to calculate the overall similarity of physiological and biochemical profiles, employing numerical taxonomy methods. The complete data matrix is available upon request. The similarity between strains was estimated with the simple-matching coefficient and cluster analysis was performed using the UPGMA (unweighted pair group method using arithmetic averages) algorithm (Sneath \& Sokal, 1973). These analyses were computed using the NTSYS-pc software package, version 2.0 (Rolf, 1998).

Comparison of isoenzyme electrophoretic patterns. Cultures were grown in liquid medium containing $0.5 \%(\mathrm{w} / \mathrm{v})$ Bactoyeast extract, $1 \%(\mathrm{w} / \mathrm{v})$ Bacto-peptone and $2 \%(\mathrm{w} / \mathrm{v})$ glucose, at $25^{\circ} \mathrm{C}$ on a rotary shaker (170 r.p.m.), until late exponential phase. Cells were harvested by centrifugation $\left(5000 \mathrm{~g}, 4^{\circ} \mathrm{C}\right.$, for $\left.7 \mathrm{~min}\right)$, washed twice with $20 \mathrm{ml}$ buffer ( $3.2 \mathrm{mmol}$ Tris $\left./ \mathrm{HCl} 1^{-1}, \mathrm{pH} 7\right)$ and stored at $-20{ }^{\circ} \mathrm{C}$ until further utilization. For protein extraction, cells were disrupted with $1 \mathrm{~g} 0.5 \mathrm{~mm}$ glass beads and $1 \mathrm{ml}$ buffer $(60 \mathrm{mmol}$ Tris $/ \mathrm{HCl} 1^{-1}$, pH 6.8) using a Mini Bead Beater cell homogenizer (Cole Parmer), at 5000 r.p.m. for 30 s, followed by cooling for $4 \mathrm{~min}$ on ice. This operation was repeated at least six times, until more than $70 \%$ of the cells were disrupted. Insoluble debris and intact cells were removed by centrifugation at $15000 \mathrm{~g}, 0{ }^{\circ} \mathrm{C}$, for $30 \mathrm{~min}$. Protein extracts were stored at $-20^{\circ} \mathrm{C}$. Five enzymes were assayed: esterase (EC 3.1.1.1), acid phosphatase (EC 3.1.3.2), lactate dehydrogenase (EC 1.1.1.27), glucose-6-phosphate dehydrogenase (EC 1.1.1.49) and alcohol dehydrogenase (EC 1.1.1.1). Electrophoresis conditions and detection of enzyme activity followed the procedures of Pasteur et al. (1987) for alcohol dehydrogenase and of Duarte et al. (1999) for the remaining enzymes. The reproducibility of the methods employed was previously checked (Santos et al., 1999). The relative electrophoretic mobilities $\left(R_{\mathrm{M}}\right)$ of the enzyme bands were calculated as the ratio of the migration of each band to that of the tracking dye and adjusted by comparison with the values obtained for Saccharomyces cerevisiae IGC 4072, electrophoresed on the same gel and used as a reference. The presence or absence of a band with a given $R_{\mathrm{M}}$ was coded with 1 or 0 , respectively, and the complete data matrix was analysed with the NTSYS-pc version 2.0 program software, using the Dice coefficient and the UPGMA clustering method.

Determination of $\mathrm{mol} \% \mathrm{G}+\mathrm{C}$ and the extent of DNA-DNA reassociation. For DNA isolation the strains were grown for 3-4 d at $22{ }^{\circ} \mathrm{C}$ in shaken YM broth (initial $\mathrm{pH}=8$ ). Cells were ruptured using a hydraulic cell press and the DNA was purified using the method of Britten et al. (1970). The nuclear DNA base composition was determined following the method of Marmur \& Doty (1962) with a Guilford Response UV-VIS Spectrophotometer and its Thermal Programming software, with nDNA from Candida parap- silosis IGC $2545^{\mathrm{T}}(\mathrm{mol} \% \mathrm{G}+\mathrm{C}=40 \cdot 2 \%)$ as reference. Values given in this report represent the means of three determinations. For DNA-DNA reassociation experiments the same instrument was used and the methods of Seidler \& Mandel (1971), as modified by Kurtzman et al. (1980), were followed. Each reassociation experiment was repeated at least three times.

PCR fingerprinting. For DNA extraction, two loopfuls of MYP-agar-grown cultures were suspended in $500 \mu$ lysing buffer $\left(50 \mathrm{mmol}\right.$ Tris $1^{-1} ; 250 \mathrm{mmol} \mathrm{NaCl} \mathrm{l}^{-1} ; 50 \mathrm{mmol}$ EDTA $\left.1^{-1} ; 0.3 \%, \mathrm{w} / \mathrm{v}, \mathrm{SDS} ; \mathrm{pH} 8\right)$ and the equivalent to a volume of $200 \mu \mathrm{l}$ of $425-600 \mu \mathrm{m}$ glass beads (Sigma) was added. After vortexing for $3 \mathrm{~min}$, the tubes were incubated for $1 \mathrm{~h}$ at $65^{\circ} \mathrm{C}$. The suspensions were then centrifuged for $30 \mathrm{~min}$ at $4{ }^{\circ} \mathrm{C}$. Nucleic acids were precipitated with $1 / 10$ volume of sodium acetate and two volumes of absolute ethanol for $24 \mathrm{~h}$ at $-20^{\circ} \mathrm{C}$. Finally, DNA was washed with ethanol $(70 \%, \mathrm{v} / \mathrm{v})$, dried and resuspended in TE (100 mmol Tris $/ \mathrm{HCl}^{-1}, \mathrm{pH} 8$, and 100 mmol EDTA $1^{-1}$ ).

Seven primers (Pharmacia Biotech) were used: four decamers (Dec. 1, ACGGTCTTGG; Dec. 2, TGCCGAGCTG; Dec. 3, TGCAGCGTGG; and Dec. 4, GGGTAACGCC; all from Prillinger et al., 1997) were employed for RAPD-PCR experiments (Welsh \& McClelland, 1990; Williams et al., 1990). The core sequence of the phage M13 (GAGGGTGGCGGTTCT) was used as a single primer in minisatellite-primed PCR experiments (Meyer et al., 1993) and two synthetic oligonucleotides, (GACA) $)_{4}$ and (GTG), were tested in microsatellite-primed PCR experiments (Meyer et al., 1993). All PCR reactions were performed in $25 \mu \mathrm{l}$ reaction volumes containing $1 \times \mathrm{PCR}$ buffer (Pharmacia, Biotech), $2 \mathrm{mmol} \mathrm{l}^{-1}$ of each of the four dNTPs (Promega), 0.8 $\mu \mathrm{mol}$ primer $^{-1}, 10-15 \mathrm{ng}$ genomic DNA and 1 U Taq DNA polymerase (Pharmacia, Biotech).

Amplification was performed in a Uno II Thermal Cycler (Biometra), consisting of an initial denaturation step at $95^{\circ} \mathrm{C}$ for $5 \mathrm{~min}$, followed by 40 cycles of $45 \mathrm{~s}$ at $93{ }^{\circ} \mathrm{C}, 60 \mathrm{~s}$ at $36^{\circ} \mathrm{C}$ (RAPD-PCR) or $50^{\circ} \mathrm{C}$ (mini and microsatellite primed PCR) and $60 \mathrm{~s}$ at $72{ }^{\circ} \mathrm{C}$ and a final extension step of $6 \mathrm{~min}$ at $72^{\circ} \mathrm{C}$. A negative control in which DNA was replaced by sterile distilled water was also included. Amplified DNA fragments were separated by electrophoresis in $1.4 \%(\mathrm{w} / \mathrm{v})$ agarose gels (Gibco-BRL) in $0.5 \times$ TBE (Trisborate-EDTA) buffer at $90 \mathrm{~V}$ for $3.5 \mathrm{~h}$, and stained with ethidium bromide. On each gel, a molecular size marker was used for reference ( $\lambda$ DNA cleaved with HindIII and $\Phi$ X174 DNA cleaved with HaeIII - Pharmacia, Biotech).

DNA banding patterns were visualized under UV transillumination and images were acquired using a Kodak Digital Science EDA 120 System and the Kodak Digital Science 1D Image Analysis Software. DNA banding patterns were analysed using the GelCompar software package, version 4.1 (Applied Maths, Kortrijk). Similarities among isolates were estimated using the Dice coefficient and clustering was based on the UPGMA method. The distortion introduced by the hierarchic grouping was estimated by comparing the values of the similarity matrix with those of the cluster analysis, to obtain a co-phenetic correlation coefficient $(r)$, based on Pearson's product-moment coefficient (Sneath \& Sokal, 1973). Low correlation $(r<0 \cdot 7)$ indicates that the taxonomic structure is being distorted by the hierarchic clustering.

The reproducibility of PCR patterns was investigated using two repeats of three randomly chosen strains. DNA used in each set of repetitions was extracted from distinct cell 
batches and the amplification reactions were performed in different PCR assays. Based on the fingerprint differences observed between each set of repeats, the probability of error was calculated according to Sneath \& Johnson (1972). This method was initially defined for phenotypic characters and is based on the binomial distribution. It can be applied when results from a large number of tests are available, in duplicate, for the same strain. In the present study, this approach was used to evaluate PCR fingerprints by considering that each band in a fingerprint is an independent character, expressed in terms of presence or absence. The probability of error $(p)$ associated with each primer was calculated using the formula $p=1-\sqrt{1-4 s^{2}}$, defined by Sneath \& Johnson (1972). The variance $\left(s^{2}\right)$ was calculated as the proportion of unmatched amplified bands in the total number of bands obtained with the two repeats of each strain.

rDNA sequence analysis. DNA was extracted using the methods described for PCR fingerprinting and amplified using primers NS7 (5'-GAG GCA ATA ACA GGT CTG TGA TGC-3') and LR6 (5'-CGC CAG TTC TGC TTA CC$\left.3^{\prime}\right)$. Cycle sequencing of the $600-650 \mathrm{bp}$ region at the $5^{\prime}$ end of the 26S rDNA D1/D2 domain employed forward primer F63 (5'-GCA TAT CAA TAA GCG GAG GAA AAG-3') and reverse primer LR3 (5'-GGT CCG TGT TTC AAG ACG G-3'). ITS cycle sequencing primers included the forward primer ITS1 (5'-TCC GTA GGT GAA CCT GCG G-3') and the reverse primer ITS4 (5'-TCC TCC GCT TAT TGA TAT GC-3'). Sequences were obtained with a Li-Cor automated sequencer using standard protocols. Alignments were made with MegAlign (DNAStar) and visually corrected. Phylogenetic trees were computed with PAUP version 4.0 using parsimony analysis (heuristic search, stepwise addition, random addition sequence, nearestneighbour interchange, 100 maximum trees). Bootstrap analysis was based on 1000 replicates.

\section{RESULTS AND DISCUSSION}

During a programme of isolating yeasts able to utilize low-molecular-mass aromatic substrates, several strains of pink yeasts were collected and identified as Rhodotorula glutinis (Sampaio, 1994). Later, two of those strains (IGC 4818 and IGC 4819) were found to be sexually compatible, producing mycelium with true clamp connections and teliospores which, upon germination, originated phragmobasidia and sessile basidiospores (Fig. 1). The sexually compatible strains IGC 4818 and IGC 4819 shared more physiological similarities with the self-sporulating species Rhodosporidium kratochvilovae than with the remaining Rhodosporidium species. Furthermore, the only relevant morphological difference that could be detected between the crossing of IGC 4818 and IGC 4819 and the strains of Rhodosporidium kratochvilovae was the absence of clamp connections in the latter. The hypothesis that the species Rhodosporidium kratochvilovae includes hitherto undescribed heterothallic strains, as suggested by both the physiological and micromorphological comparisons, was tested using different approaches.

Based on the overall similarity of physiological data, Sampaio \& Fonseca (1995) observed that strains of

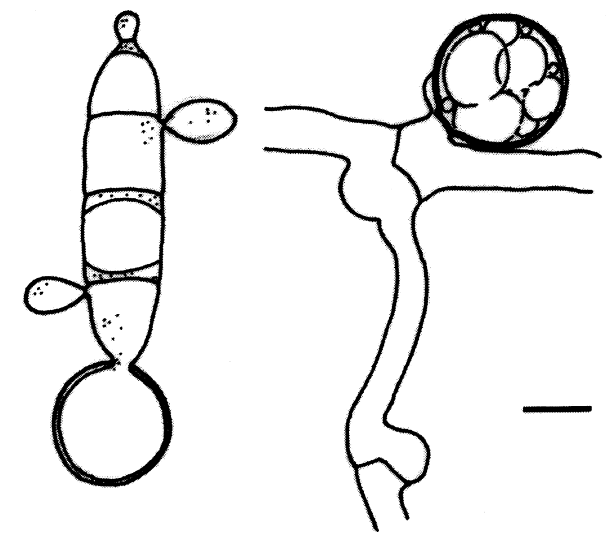

Fig. 1. Line drawing of hyphae, teliospores, basidium and basidiospores resulting from the crossing of IGC 4818 and IGC 4819 on CMA after 1 month at room temperature. The teliospore on the left germinated and originated a four-celled basidium. The teliospore on the right is still attached to the mycelium (note the complete clamp connections). Bar, $5 \mu \mathrm{m}$.

Rhodotorula glutinis clustered in two distinct main groups, one including the type strain of the species and the other including IGC 4883, an anamorphic strain of Rhodosporidium kratochvilovae. Some of the strains investigated in that study were also included in the present report in order to check their identity.

\section{PCR fingerprinting and isoenzyme analysis}

Reproducibility of PCR fingerprinting was evaluated in preliminary experiments by estimating the probability of error associated with each primer. Decamer 4 and (GACA) $)_{4}$ were rejected, given their poor reproducibility in repeated PCR experiments $(p=$ 0.237 and $0 \cdot 259$, respectively). The remaining five primers showed clear and reproducible patterns and the values of $p$ were 0 for primer M13, 0.032 for primer $(\mathrm{GTG})_{5}$ and varied between 0.061 and 0.075 for the remaining RAPD primers. Therefore their ability to produce species-specific profiles was investigated with a selected group of strains. The dendrogram resulting from the combined numerical analysis of the PCR profiles obtained with the five primers is shown in Fig. 2 . Besides the two self-sporulating strains (IGC $4583^{\mathrm{T}}$ and IGC 5579) reported in the original description, the Rhodosporidium kratochvilovae cluster contained a recent isolate of a self-sporulating Rhodosporidium sp. (IGC 4793), two strains considered as anamorphs of Rhodosporidium kratochvilovae (IGC 4883 and IGC 5580), two other strains (IGC 5591 and IGC 5606) reported as related to the type strain of Rhodosporidium kratochvilovae based on the analysis of whole-cell protein patterns (Vancanneyt et al., 1992), the two above-mentioned sexually compatible strains (IGC 4818 and IGC 4819), and IGC 4776, IGC 4778, IGC 4785 and IGC 4787, which had been previously identified as Rhodotorula glutinis (Sampaio \& Fonseca, 1995). A similar delimitation of the Rhodosporidium 


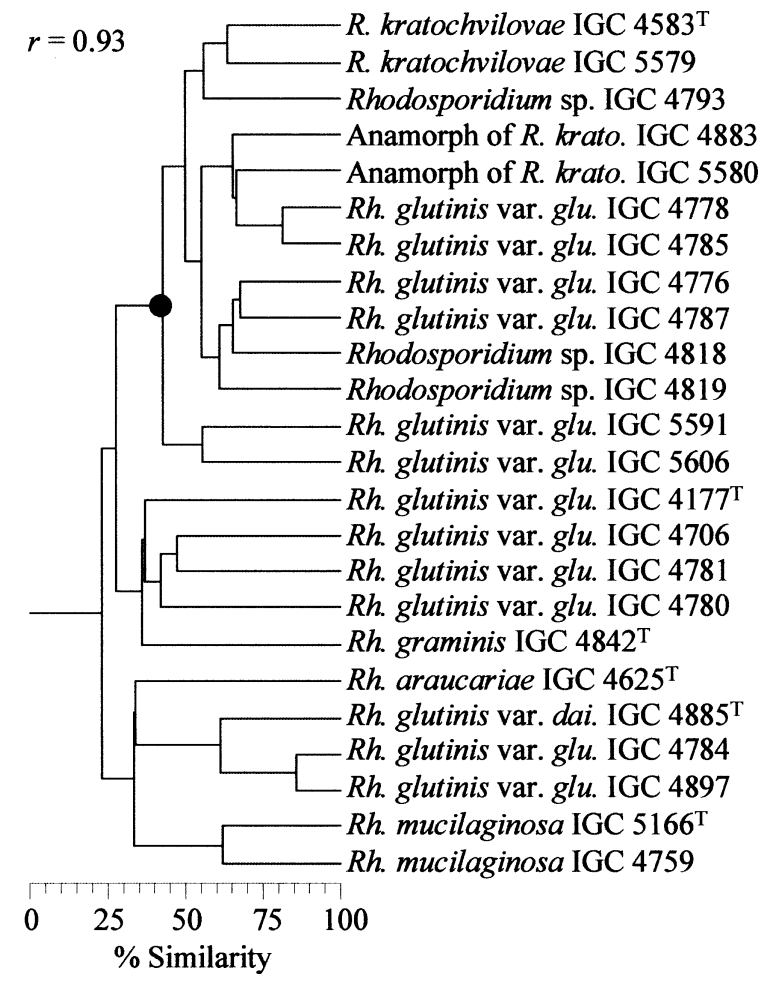

Fig. 2. Dendrogram of selected strains of Rhodosporidium and Rhodotorula based on the combined analysis of the PCR fingerprints obtained with primers Decamer 1, Decamer 2, Decamer 3, (GTG) $)_{5}$ and M13, using the Dice coefficient and the UPGMA cluster method ( $r$, co-phenetic correlation coefficient). The black circle indicates the node corresponding to the Rhodosporidium kratochvilovae cluster.

kratochvilovae cluster was observed using the electrophoretic patterns of five isoenzyme systems (Fig. 3). These results support the hypothesis that all the strains in this group belong to a single species. In spite of the agreement between the PCR fingerprinting (Fig. 2) and isoenzyme analysis (Fig. 3), a discrepant result was observed for Rhodotorula glutinis IGC 4784, if previously published data are taken into consideration. This strain was characterized as a member of the Rhodosporidium kratochvilovae group based on physiological data (Sampaio \& Fonseca, 1995), but clustered outside this group and close to the type strain of Rhodotorula glutinis var. dairenensis Hasegawa et Banno in both analyses of the present study.

To determine the stability of the Rhodosporidium kratochvilovae cluster, a larger set of strains was studied, including representatives of all the other Rhodosporidium species (Table 1). The PCR fingerprinting method was employed but only two primers were used. The selected primers were M13 and (GTG) due to their higher reproducibility and their ability to produce homogeneous and species-specific profiles. The DNA fingerprints and the dendrogram resulting from the combined numerical analysis of the PCR profiles obtained with the two primers are shown in

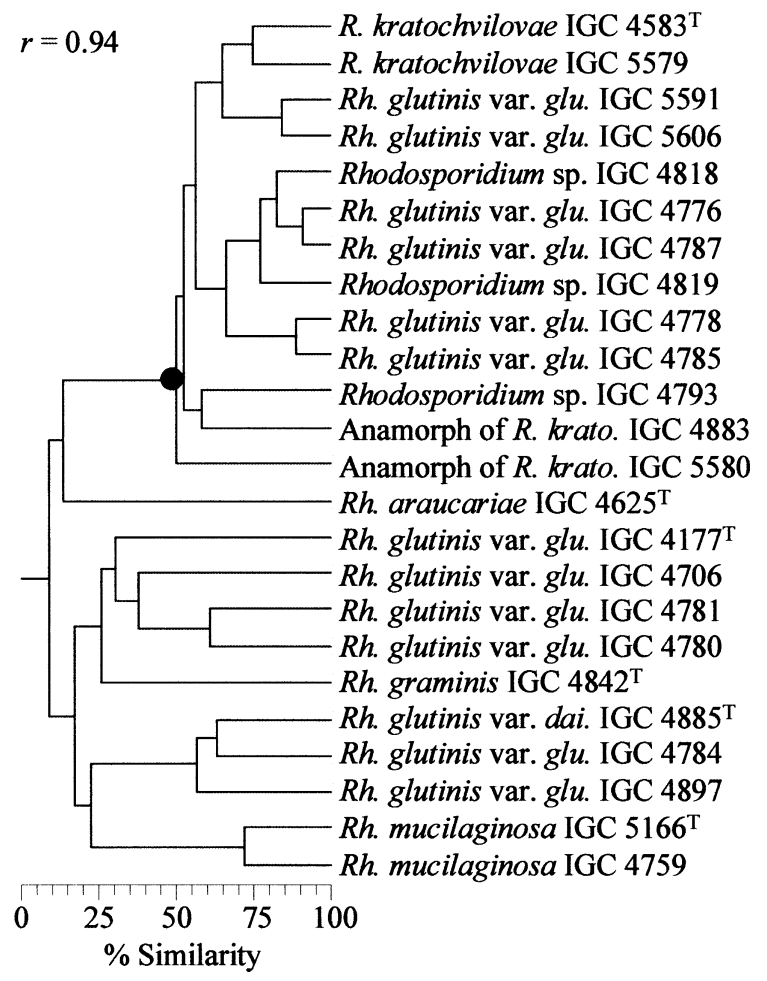

Fig. 3. Dendrogram of selected strains of Rhodosporidium and Rhodotorula based on the combined analysis of the electrophoretic patterns of the enzymes esterase, acid phosphatase, lactate dehydrogenase, glucose-6-phosphate dehydrogenase and alcohol dehydrogenase, using the Dice coefficient and the UPGMA cluster method ( $r$, co-phenetic correlation coefficient). The black circle indicates the node corresponding to the Rhodosporidium kratochvilovae cluster.

Fig. 4. All species of the genus Rhodosporidium originated distinct patterns and therefore Rhodosporidium kratochvilovae was clearly separated from the other members of the genus. Moreover, four additional strains (IGC 4783, IGC 5068, IGC 5085 and IGC 5244), previously identified as Rhodotorula glutinis, originated Rhodosporidium kratochvilovaetype PCR fingerprints (Fig. 4).

\section{Species delimitation}

The results from PCR fingerprinting and isoenzyme approaches suggested that several teleomorphic and anamorphic strains might represent additional members of Rhodosporidium kratochvilovae. To test this hypothesis, a selected group of strains was investigated with other methodologies. The methods used at this stage were determination of $\mathrm{mol} \% \mathrm{G}+\mathrm{C}$, assessment of the degree of DNA-DNA hybridization, determination of the relatedness of $26 \mathrm{~S}$ rDNA sequences and investigation of sexual compatibility.

The $\mathrm{mol} \% \mathrm{G}+\mathrm{C}$ values (thermal denaturation method) determined in this study were $70 \cdot 2 \pm 0 \cdot 18$ and $69 \cdot 9 \pm 0 \cdot 15$ for the self-sporulating strains IGC $4583^{\mathrm{T}}$ 


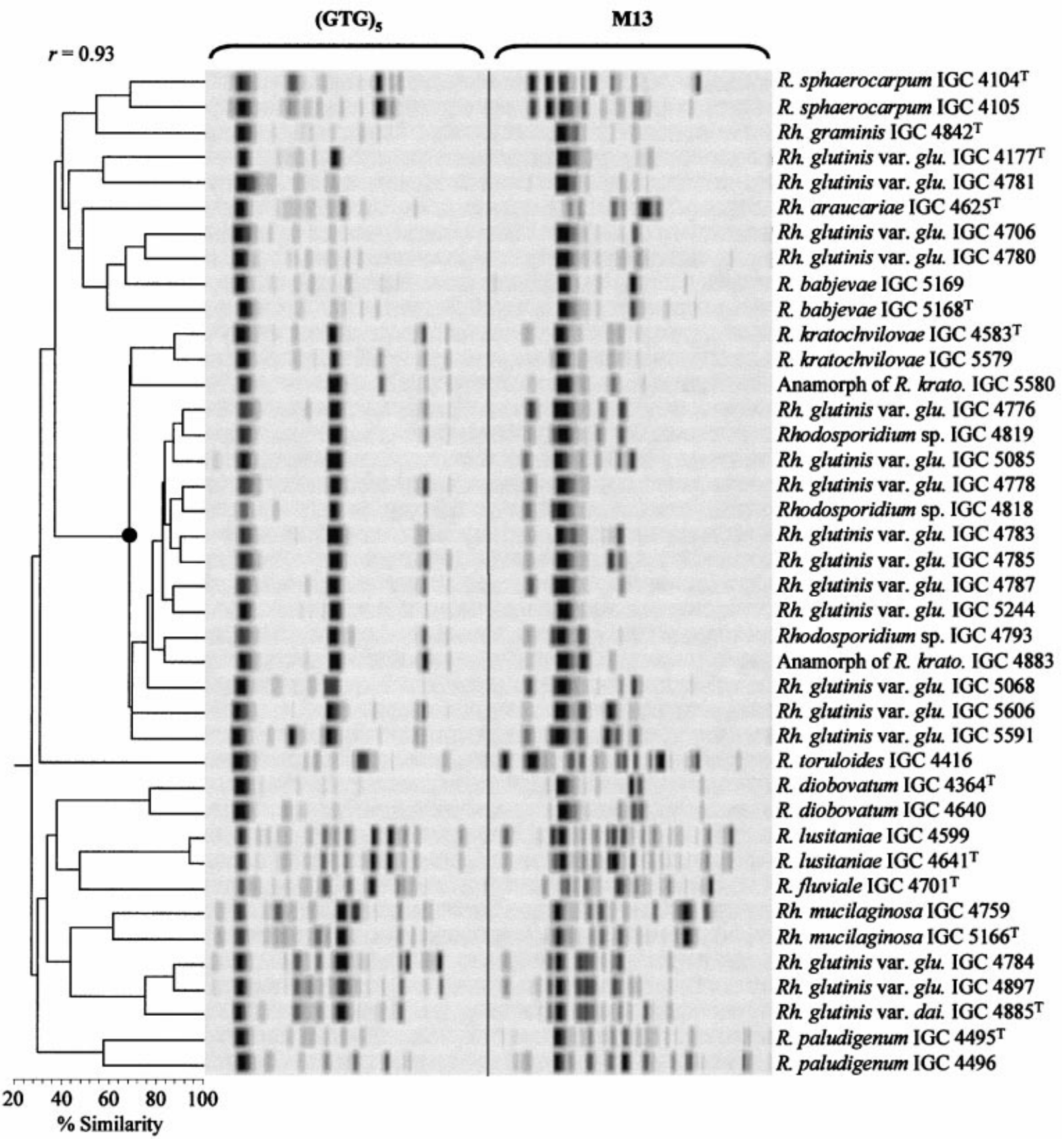

Fig. 4. DNA banding patterns and resulting dendrogram of selected strains of Rhodosporidium and Rhodotorula based on the combined analysis of the PCR fingerprints obtained with primers (GTG) $)_{5}$ and M13, using the Dice coefficient and the UPGMA cluster method ( $r$, co-phenetic correlation coefficient). The black circle indicates the node corresponding to the Rhodosporidium kratochvilovae cluster.

and IGC 5579, respectively, and $68 \cdot 7 \pm 0 \cdot 17$ and $68 \cdot 9 \pm 0 \cdot 12$ for the anamorphic strains of Rhodosporidium kratochvilovae IGC 4883 and IGC 5580, respectively. The $\mathrm{mol} \% \mathrm{G}+\mathrm{C}$ values obtained for IGC 4793 (self-sporulating) and IGC 4818 (mating type) were $70 \cdot 9 \pm 0 \cdot 14$ and $71 \cdot 3 \pm 0 \cdot 25$, respectively. Since the mol $\% \mathrm{G}+\mathrm{C}$ values of IGC 4793 and IGC 4818 were similar to the values determined for the reference strains, the hypothesis that both strains belong to Rhodosporidium kratochvilovae could not be rejected. On the other hand, Rhodotorula glutinis IGC 4784, the strain clustering close to Rhodotorula glutinis var. dairenensis in the PCR fingerprinting and isoenzyme analysis, had a mol $\% \mathrm{G}+\mathrm{C}$ of $64 \cdot 9 \pm 0 \cdot 22$. This value was similar to the one obtained for the type strain of Rhodotorula glutinis var. dairenensis (mol\% $\mathrm{G}+\mathrm{C}$ of IGC $4885^{\mathrm{T}}=64 \cdot 9 \pm 0 \cdot 18$ ). To determine the conspecificity of IGC 4793 and IGC 4818 with Rhodo- 


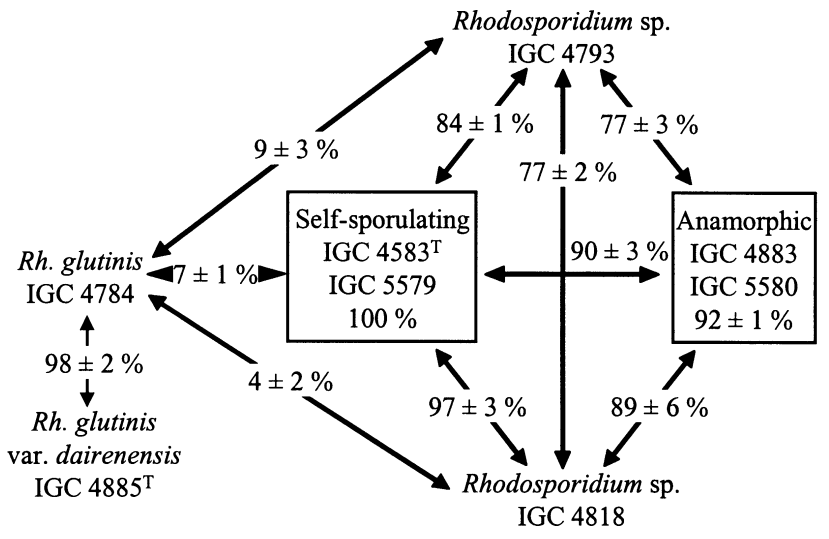

Fig. 5. Results of DNA-DNA reassociation experiments involving strains of Rhodosporidium kratochvilovae and Rhodotorula glutinis var. dairenensis.

sporidium kratochvilovae and to clarify the relationship of IGC 4784 with Rhodotorula glutinis var. dairenensis, DNA-DNA reassociation experiments were performed as depicted in Fig. 5. Considering the homology values higher than $70 \%$ as an evidence of conspecificity, we confirmed that IGC 4793 and IGC 4818 belong to Rhodosporidium kratochvilovae whereas IGC 4784 is a member of Rhodotorula glutinis var. dairenensis. Therefore, IGC 4818 is designated mating type A1 of Rhodosporidium kratochvilovae and IGC 4819 mating type A2. The two compatible strains were then used to detect additional heterothallic strains among the anamorphic strains found in the Rhodosporidium kratochvilovae cluster (Figs 2, 3 and 4). The strains IGC 4818 and IGC 4819 were crossed, separately, with the remaining non self-sporulating strains. Results were scored positive when mycelium with clamp connections and teliospores was produced. The currently recognized strains of Rhodosporidium kratochvilovae and their type of sexuality are depicted in Table 2. Most of the Rhodotorula glutinis strains included in the Rhodosporidium kratochvilovae cluster were found to belong to one of the two mating types of Rhodosporidium kratochvilovae. The strain IGC 4883, previously characterized as an anamorphic stage of Rhodosporidium kratochvilovae (Hamamoto et al., 1988), is in fact a heterothallic strain, although positive mating reactions were infrequent and difficult to detect due to the scarcity of mycelium with teliospores. Weak mating reactions also occurred with strain IGC 4776. Moreover, when the self-sporulating strain IGC 4793 was crossed with strain IGC 4819 (mating type A2), besides the self-sporulating mycelium with incomplete clamp connections, some branches of mycelium with true clamp connections were detected. This observation suggests that IGC 4793 behaves as either a selfsporulating or a heterothallic strain. This phenomenon did not occur when crossings were performed with the opposite mating type or in crossings involving other heterothallic and self-sporulating strains. Absence of mating reactions was recorded for four strains (Table 2). Since these strains repeatedly failed to demonstrate any type of sexual compatibility and as a consequence no sexual state has been observed, we consider that they should not be designated Rhodosporidium kratochvilovae. On the other hand, it seems redundant to propose a new Rhodotorula species to accommodate these isolates since, according to currently used taxonomic criteria, namely DNA-DNA reassociation values, the sexual and asexual strains of the Rhodosporidium kratochvilovae cluster are conspecific. Therefore we propose the designation 'anamorphic state of

Table 2 Sexuality and physiological traits of Rhodosporidium kratochvilovae strains

Data from Rhodotorula glutinis are included for comparison. Sex., sexuality; Ss, self-sporulating; Mt, mating type; An, anamorphic; Xil., xylitol; Cx 100, cycloheximide 100 p.p.m.; Cx 1000, cycloheximide 1000 p.p.m.; Ga., gallic acid; Cat., catechol; Vit., growth without vitamins; $35^{\circ} \mathrm{C}$, growth at $35^{\circ} \mathrm{C}$.

\begin{tabular}{|c|c|c|c|c|c|c|c|c|c|}
\hline Species & Strain & Sex. & Xil. & Cx 100 & Cx 1000 & Ga. & Cat. & Vit. & $35^{\circ} \mathrm{C}$ \\
\hline Rhodosporidium kratochvilovae & IGC $4583^{\mathrm{T}}$ & Ss & - & - & - & + & + & + & - \\
\hline Rhodosporidium kratochvilovae & IGC 5579 & Ss & - & - & - & + & + & + & - \\
\hline Rhodosporidium kratochvilovae & IGC 4793 & Ss, Mt A1 & - & - & - & + & + & + & - \\
\hline Rhodosporidium kratochvilovae & IGC 4818 & Mt Al & - & - & - & + & + & + & - \\
\hline Rhodosporidium kratochvilovae & IGC 5244 & Mt Al & - & - & - & + & + & + & + \\
\hline Rhodosporidium kratochvilovae & IGC 4776 & Mt A2 & - & - & - & + & + & + & - \\
\hline Rhodosporidium kratochvilovae & IGC 4778 & Mt A2 & - & - & - & + & + & + & - \\
\hline Rhodosporidium kratochvilovae & IGC 4783 & Mt A2 & - & - & - & + & + & + & - \\
\hline Rhodosporidium kratochvilovae & IGC 4785 & Mt A2 & - & - & - & + & + & + & - \\
\hline Rhodosporidium kratochvilovae & IGC 4819 & Mt A2 & - & - & - & + & + & + & - \\
\hline Rhodosporidium kratochvilovae & IGC 4883 & Mt A2 & - & - & - & + & + & + & - \\
\hline Rhodosporidium kratochvilovae & IGC 5068 & Mt A2 & - & - & - & + & + & + & - \\
\hline Rhodosporidium kratochvilovae & IGC 5085 & Mt A2 & - & - & - & + & + & + & + \\
\hline Anamorph of Rhodosporidium kratochvilovae & IGC 4787 & An & - & - & - & + & + & + & - \\
\hline Anamorph of Rhodosporidium kratochvilovae & IGC 5580 & An & - & - & - & + & + & + & - \\
\hline Anamorph of Rhodosporidium kratochvilovae & IGC 5591 & An & - & - & - & + & + & + & + \\
\hline Anamorph of Rhodosporidium kratochvilovae & IGC 5606 & An & - & - & - & + & + & + & + \\
\hline Rhodotorula glutinis var. glutinis & $\mathrm{IGC} 4177^{\mathrm{T}}$ & An & + & + & + & - & - & + & - \\
\hline Rhodotorula glutinis var. dairenensis & IGC $4885^{\mathrm{T}}$ & An & + & + & + & - & - & - & + \\
\hline Rhodotorula glutinis var. dairenensis & IGC 4784 & An & + & + & + & - & - & - & + \\
\hline Rhodotorula glutinis var. dairenensis & IGC 4897 & An & + & + & + & - & - & - & + \\
\hline
\end{tabular}




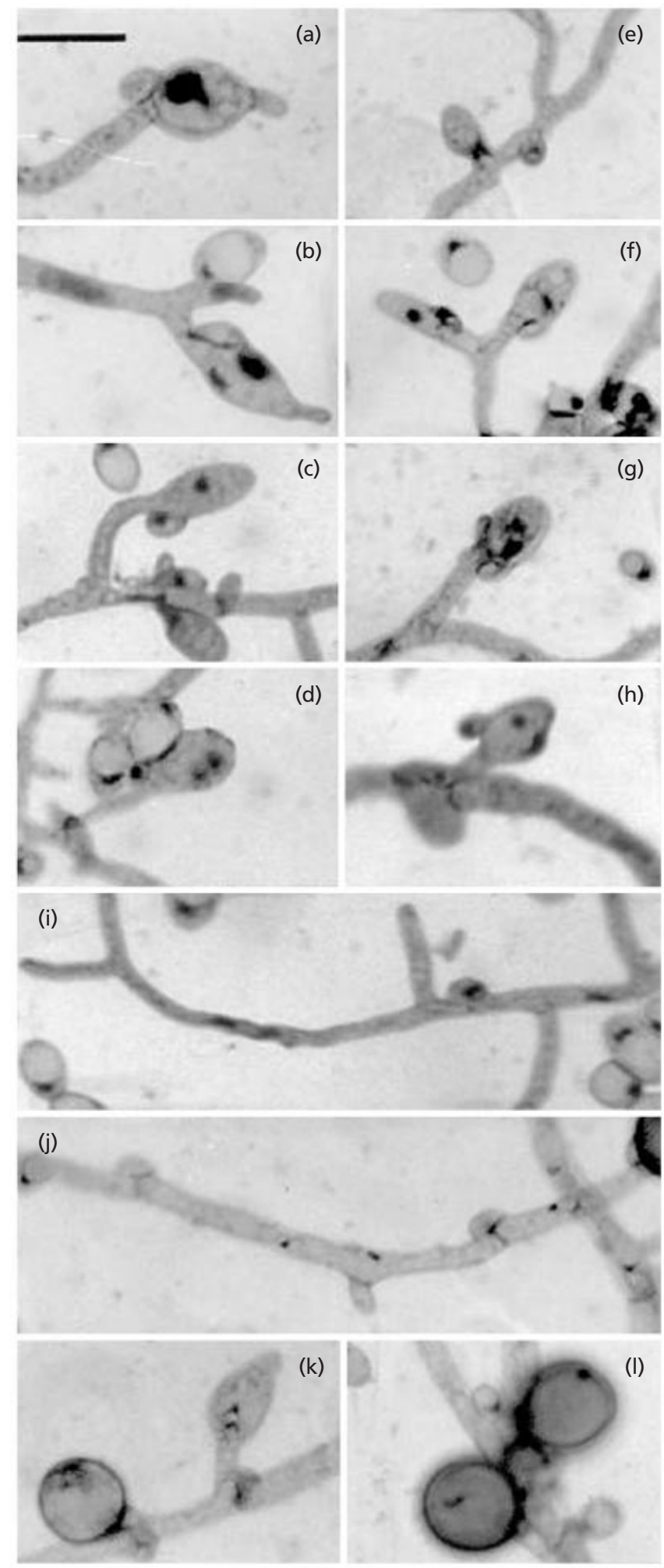

Fig. 6. Giemsa's staining micrographs of strains of Rhodosporidium kratochvilovae grown on CMA for 1 week at room temperature. (a)-(d) IGC 4583'; (e)-(i) IGC 4793; (j)-(I) IGC $4785 \times$ IGC 4818. Bar, $10 \mu \mathrm{m}$.
Rhodosporidium kratochvilovae' to be applied in such cases.

The nuclear behaviour of Rhodosporidium kratochvilovae was studied with Giemsa staining and selected micrographs are presented in Fig. 6. Giemsa staining revealed that the mycelium resulting from the crossing of heterothallic strains was dikaryotic (Fig. $6 \mathrm{j})$. The mycelium of the self-sporulating strains was also dikaryotic, one of the nuclei usually being retained in the incomplete clamp connection. In some cases, three nuclei could be observed per mycelial compartment (Fig. 6i). This could be the result of the division of the free nucleus and suggests that the mycelium is functionally homo-dikaryotic. In the heterothallic strains, teliospores were dikaryotic immediately after formation (Fig. 6k) but, when mature, only one nucleus was observed (Fig. 61). In the self-sporulating strains IGC $4583^{\mathrm{T}}$ and IGC 4793, nuclear behaviour in the teliospore was difficult to interpret. Based on micrographs of teliospores in different developmental stages, we tentatively propose the following sequence of events: (i) young teliospores have a single nucleus (if present, the incomplete clamp connection at the base of the teliospore has no nucleus at this stage) (Fig. 6a, e and f); (ii) the nucleus divides in the teliospore (Fig. 6b, g); (iii) one of the resulting two nuclei migrates to the incomplete clamp connection at the base of the teliospore (Fig. 6c); the nucleus that remained in the teliospore divides again (Fig. 6d, h); (iv) the two nuclei in the teliospore fuse and the teliospore becomes uninucleate but diploid (micrographs not shown but identical to Fig. 61). In conclusion, Rhodosporidium kratochvilovae seems to be dikaryotic and then diploid, either in the heterothallic or in the self-sporulating condition. This suggests that meiosis takes place as usual, and would explain why the basidia of the self-sporulating strains have the typical four compartments instead of two. The main difference between heterothallic and selfsporulating life cycles would be, respectively, the heterokaryotic versus homokaryotic condition of the dikaryon.

To compare the information given by the different approaches aiming at species recognition, the D1/D2 region of the $26 \mathrm{~S}$ rDNA of a selected group of strains was sequenced and compared with available sequences from related species (Fig. 7). No nucleotide differences were found among the Rhodosporidium kratochvilovae strains or among the three strains of Rhodotorula glutinis var. dairenensis studied. Due to their usefulness in the discrimination of closely related taxa (Fell et al., 2000), the ITS sequences of a restricted number of strains of Rhodosporidium kratochvilovae were determined. No base pair differences were found between IGC $4583^{\mathrm{T}}$ (self-sporulating), IGC 4818 (mating type) and IGC 5591 (anamorph). Therefore, sequence data concur with the other taxonomic criteria used in this work and point to the presence of a single species in the Rhodosporidium kratochvilovae cluster, irrespective of the different types of sexuality found. 


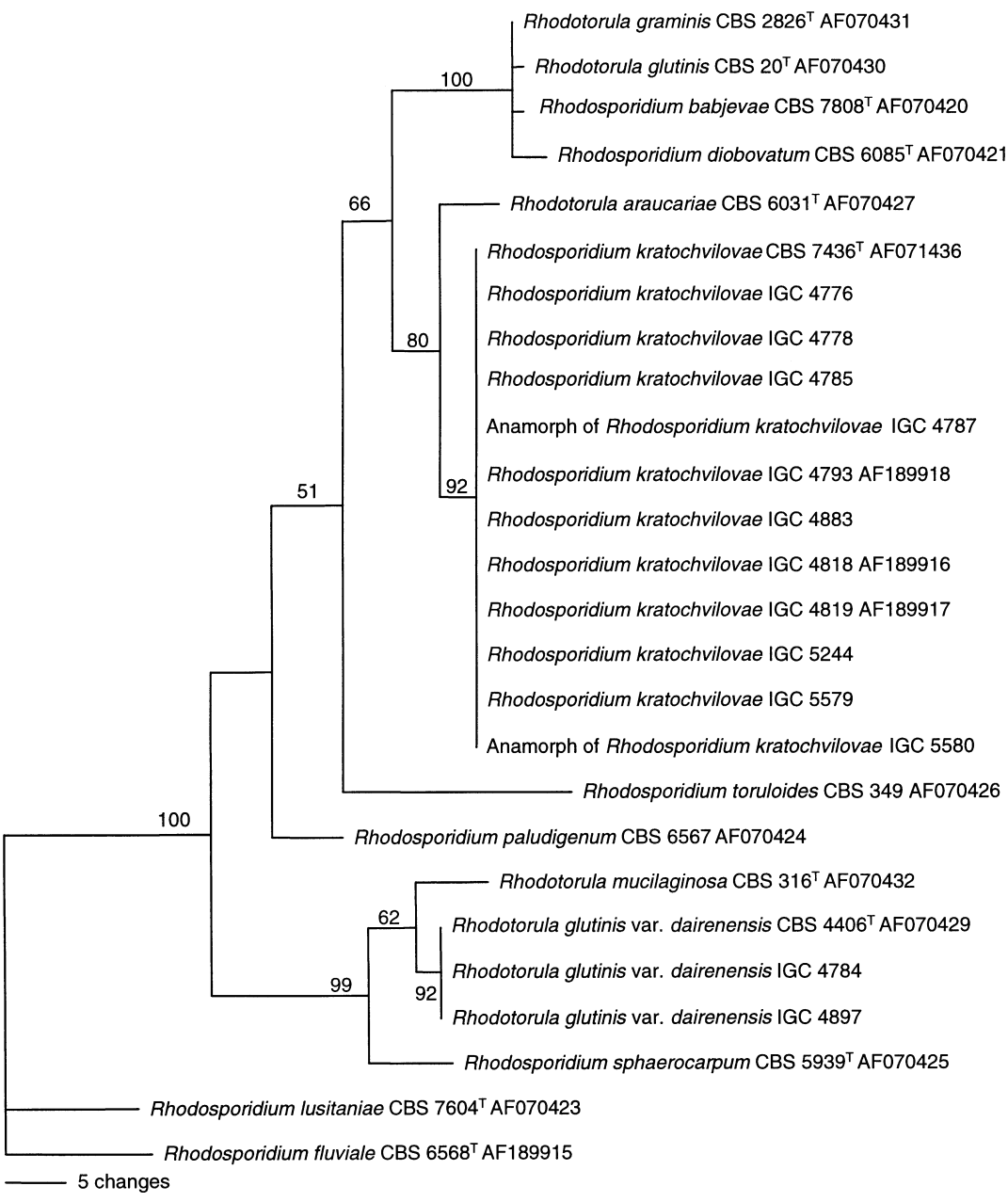

Fig. 7. Phylogenetic tree of Rhodosporidium kratochvilovae and related species, obtained by parsimony analysis (heuristic search, random addition, nearest neighbour interchange, 100 maximum trees) of the D1/D2 region of the $26 \mathrm{~S}$ rDNA. Branch lengths are proportional to the number of nucleotide differences and the numbers given on the branches are the bootstrap values ( $>50 \%$ ) of 1000 replicates. GenBank accession numbers are indicated after species and strain designation.
To improve the phenotypic recognition of Rhodosporidium kratochvilovae, the physiological characterization of the species was re-evaluated using conventional and non-conventional physiological tests. All tests that previously gave variable responses for the strains of the Rhodosporidium kratochvilovae cluster, as defined by molecular methods, were repeated. In some cases, the variable results were confirmed but in other cases, uniform responses were detected, which contributed to a better phenotypic circumscription of the species. The physiological profiles of IGC 4783 and IGC 4784 were also checked due to the discrepancies found between previously published data (Sampaio \& Fonseca, 1995) and the present study. For these two strains, some of the former results were found to be incorrect. The revised physiological data were analysed using the overall similarity approach (Fig. 8). The results were in accordance with the data derived from the other approaches presented above (Figs 2, 3, 4, 5 and 7). Salient physiological characteristics of Rhodosporidium kratochvilovae, allowing the discrimination from Rhodotorula glutinis, are listed in Table 2. The reinvestigation of physiological characteristics indicates that a relationship with Rhodosporidium kratochvilovae can be presumed for anamorphic strains falling in the general delimitation of Rhodotorula glutinis (i.e. pink-coloured, inositol-negative, melezitose-positive and nitrate-positive), but unable to grow in the presence of cycloheximide, unable to utilize xylitol and capable of using the aromatic compounds gallic acid and catechol.

Based on sequence data from the D1/D2 region of the 26S rDNA, Fell et al. (1998) observed that the type strain of Rhodotorula glutinis var. dairenensis was clearly distinct from the type strain of Rhodotorula glutinis var. glutinis. These results, as well as those presented in our study, indicate that Rhodotorula glutinis var. dairenensis should be placed in a species of its own. However, a detailed characterization of additional isolates of Rhodotorula glutinis var. dairenensis should be accomplished prior to any formal taxonomic proposal.

Integrated polyphasic studies of basidiomycetous yeasts, such as the one presented in this investigation, contribute to expanding our knowledge on the genetic and phenotypic boundaries of species. Another important aspect is the unveiling of new anamorphteleomorph connections in order to reduce the recognized heterogeneity of taxa such as Rhodotorula glutinis. Moreover, these studies allow the evaluation of different taxonomic approaches currently available. 


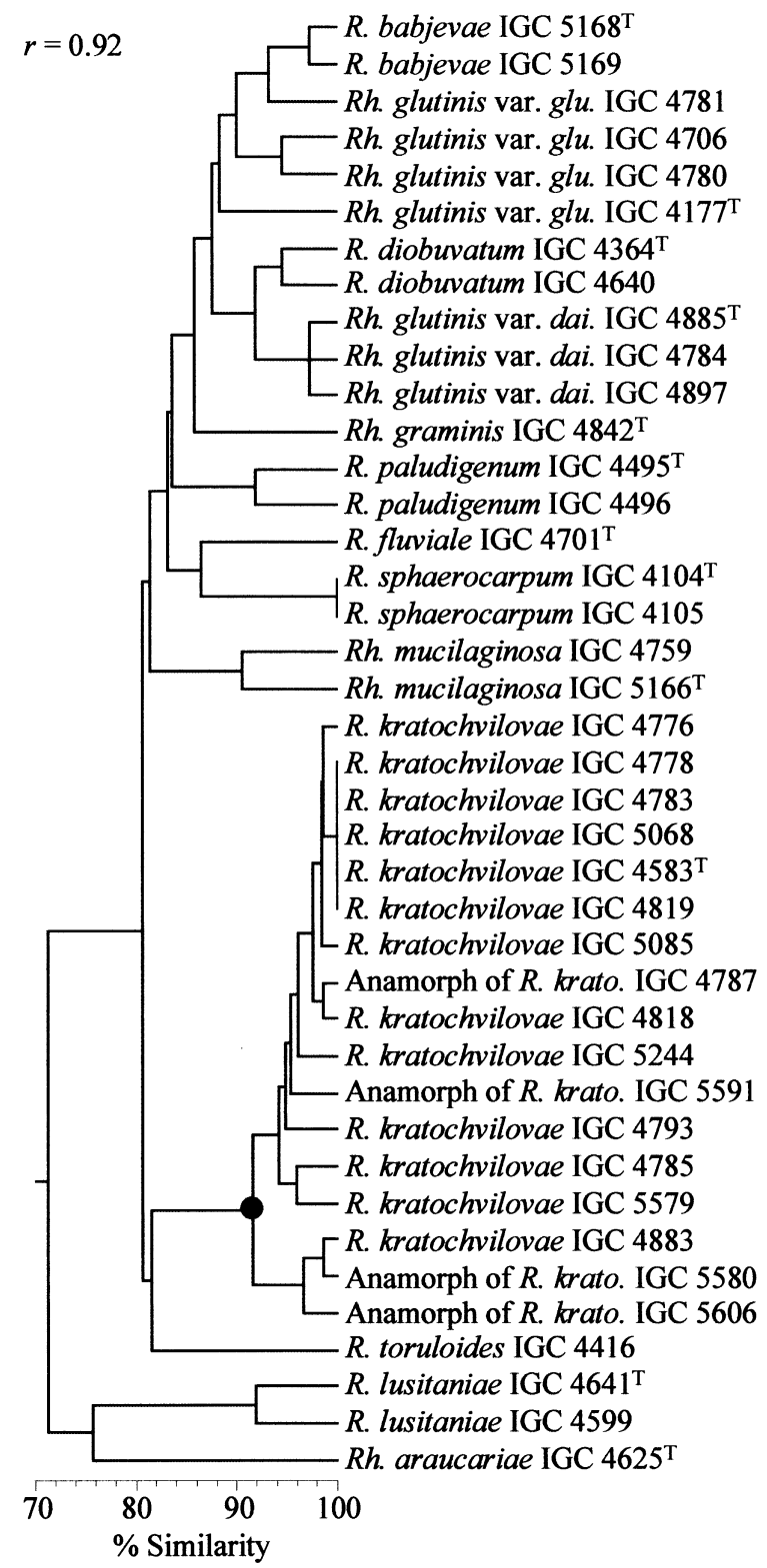

Fig. 8. Phenogram of Rhodosporidium and related Rhodotorula species based on the overall similarity (simple matching coefficient) and cluster analysis (UPGMA) of 78 physiological tests ( $r$, co-phenetic correlation coefficient). The black circle indicates the node corresponding to the Rhodosporidium kratochvilovae cluster.

In the present case, the microsatellite-primed PCR fingerprinting method using the M13 and (GTG) primers proved to be suitable for the discrimination of the species under study. Since it allows a rapid and accurate investigation of a large number of strains, this procedure is currently used in our laboratory for the molecular identification of environmental isolates. In the future, the study of other species in the genus Rhodosporidium will allow a thorough reassessment of the traditional morphological and physiological criteria currently used in the taxonomy of this genus.
These efforts will conceivably result in a more natural classification system and will improve our understanding of the ecology of the different Rhodosporidium species.

\section{ACKNOWLEDGEMENTS}

This work was financially supported by grant PRAXIS/ PCNA/C/BIA/174/96 (FCT, Portugal). M.G. was supported by grant PRAXIS/BTI/16804/98 and J.W.F. was supported by a grant from the National Sciences Foundation (Biological Oceanography). The authors are indebted to Professor Isabel Spencer-Martins for critical reading of the manuscript.

\section{REFERENCES}

Bandoni, R. J. (1972). Terrestrial occurrence of some aquatic hyphomycetes. Can J Bot 50, 2283-2288.

Britten, R. J., Pavich, M. \& Smith, J. (1970). A new method of DNA purification. Carnegie Inst Wash Year Book 68, 400-402.

Duarte, F. L., Pais, C., Spencer-Martins, I. \& Leão, C. (1999). Distinctive electrophoretic isoenzyme profiles in Saccharomyces sensu stricto. Int J Syst Bacteriol 49, 1907-1913.

Fell, J. W., Blatt, G. M. \& Statzell-Tallman, A. (1998). Validation of the basidiomycetous yeast, Sporidiobolus microsporus sp. nov., based on phenotypic and molecular analyses. Antonie Leeuwenhoek 74, 265-270.

Fell, J. W., Boekhout, T., Fonseca, A., Scorzetti, G. \& StatzellTallman, A. (2000). Biodiversity and systematics of basidiomycetous yeasts as determined by large subunit rDNA D1/D2 domain sequence analysis. Int $J$ Syst Evol Microbiol 50, 1351-1371.

Fonseca, A. (1992). Utilization of tartaric acid and related compounds by yeasts: taxonomic implications. Can J Microbiol 38, 1242-1251.

Hamamoto, M., Sugiyama, J., Goto, S. \& Komagata, K. (1986a). Numerical taxonomy based on the electrophoretic mobility of enzymes in the genera Rhodosporidium, Cystofilobasidium and Rhodotorula. J Gen Appl Microbiol 32, 89-99.

Hamamoto, M., Sugiyama, J. \& Komagata, K. (1986b). DNA base composition of strains in the genera Rhodosporidium, Cystofilobasidium and Rhodotorula determined by reversed-phase high-performance liquid chromatography. J Gen Appl Microbiol 32, 215-223.

Hamamoto, M., Sugiyama, J. \& Komagata, K. (1987). DNA-DNA reassociation studies of strains in the genera Rhodosporidium and Rhodotorula. J Gen Appl Microbiol 33, 57-73.

Hamamoto, M., Sugiyama, J. \& Komagata, K. (1988). Rhodosporidium kratochvilovae sp. nov., a new basidiomycetous yeast species. J Gen Appl Microbiol 34, 119-125.

Kurtzman, C. P., Smiley, M. J., Johnson, C. J., Wickerham, L. J. \& Fuson, G. B. (1980). Two closely related heterothallic species, Pichia amylophila and Pichia mississipiensis: characterization by hybridization and deoxyribonucleic acid reassociation. Int $J$ Syst Bacteriol 30, 208-216.

Marmur, J. \& Doty, P. (1962). Determination of the base composition of DNA from its thermal denaturation temperature. J Mol Biol 5, 109-118.

Meyer, W., Mitchell, T. G., Freedman, E. Z. \& Vilgalys, R. (1993). Hybridization probes for conventional DNA fingerprinting used as single primers in the polymerase chain reaction to 
distinguish strains of Cryptococcus neoformans. J Clin Microbiol 31, 2274-2280.

Pasteur, N., Pasteur, G., Bonhomme, F., Catalan, J. \& BrittonDavidian, J. (1987). Manuel Technique de Génétique par Électrophorèse des Protéines. Lavoisier Technical Document, Paris.

Prillinger, H., Kraepelin, G., Lopandic, K., Schweigkofler, W., Molnár, O., Weigang, F. \& Dreyfuss, M. M. (1997). New species of Fellomyces isolated from epiphytic lichen species. Syst Appl Microbiol 20, 572-584.

Rolf, F. J. (1998). NTSYS-pc. Numerical Taxonomy and Multivariate Analysis System, version 2.0. New York: Applied Biostatistics.

Sampaio, J. P. (1994). Utilization of low molecular weight ligninrelated aromatic compounds for the selective isolation of yeasts: Rhodotorula vanillica, a new basidiomycetous yeast species. Syst Appl Microbiol 17, 613-619.

Sampaio, J.P. (1999). Utilization of low molecular weight aromatic compounds by heterobasidiomycetous yeasts: taxonomic implications. Can J Microbiol 45, 491-512.

Sampaio, J. P. \& Fonseca, A. (1995). Physiological aspects in the systematics of heterobasidiomycetous yeasts. Stud Mycol 38, $29-46$.

Santos, S., Duarte, F. L. \& Pais, C. (1999). Stability of yeast isoenzyme profiles in different growth conditions. Food Technol Biotechnol 37, 263-269.

Seidler, R. J. \& Mandel, M. (1971). Quantitative aspects of deoxyribonucleic acid renaturation: base composition, site of chromosome replication, and polynucleotide homologies. $J$ Bacteriol 106, 608-614.
Sneath, P. H. A. \& Johnson, R. (1972). The influence on numerical taxonomic similarities of errors in microbiological tests. J Gen Microbiol 72, 377-392.

Sneath, P. H. A. \& Sokal, R. R. (1973). Numerical Taxonomy. San Francisco: W. H. Freeman.

Sugiyama, J., Fukagawa, M., Chiu, S.-W. \& Komagata, K. (1985). Cellular carbohydrate composition, DNA base composition, ubiquinone systems, and diazonium blue B color test in the genera Rhodosporidium, Leucosporidium, Rhodotorula and related basidiomycetous yeasts. J Gen Appl Microbiol 31, 519-550.

Vancanneyt, M., Coopman, R., Tytgat, R., Berny, J.-F., Hennebert, G. L. \& Kersters, K. (1992). A taxonomic study of the basidiomycetous yeast genera Rhodosporidium Banno and Rhodotorula Harrison based on whole-cell protein patterns, DNA base compositions and coenzyme Q types. J Gen Appl Microbiol 38, 363-377.

Welsh, J. \& McClelland, M. (1990). Fingerprinting genomes using PCR with arbitrary primers. Nucleic Acids Res 18, 7213-7224.

Williams, J. G. K., Kubelik, A. R., Livak, K. J., Rafalski, J. A. \& Tingey, S. V. (1990). DNA polymorphisms amplified by arbitrary primers are useful as genetic markers. Nucleic Acids Res 18, 6531-6535.

Yamazaki, M. \& Komagata, K. (1981). Taxonomic significance of electrophoretic comparison of enzymes in the genera Rhodotorula and Rhodosporidium. Int J Syst Bacteriol 31, 361-381.

Yarrow, D. (1998). Methods for the isolation, maintenance and identification of yeasts. In The Yeasts, a Taxonomic Study, 4th edn, pp. 77-100. Edited by C. P. Kurtzman \& J. W. Fell. Amsterdam: Elsevier. 